\title{
New Law and Policy
}

This journal section features a selection of the most noteworthy developments in chemical law and policy. The notes are sourced from the European Commission, ECHA and other relevant international institutions. This section was compiled by Lara Dickens.

\section{EU Updates Rules for Persistent Organic Pollutants}

On $13^{\text {th }}$ June 2019, the European Union adopted tighter rules ${ }^{1}$ for the world's most dangerous chemicals - persistent organic pollutants - enhancing the protection of people and the environment from these chemicals. The EU rules align with the most recent amendments to the Stockholm Convention, an international treaty that requires parties to take measures to eliminate or reduce the release of Persistent Organic Pollutants (POPs) into the environment. Exposure to POPs can lead to serious health effects including certain cancers, birth defects or dysfunctional immune systems.

Following a European Commission proposal to recast the POPs regulation in March 2018, and subsequent discussions by the Council and Parliament the adoption of the text paves the way for publication in the Official Journal of the European Union. Under the EU regulation, the flame retardant decaBDE is added to the list of substances and the unintentional trace contaminant value is set at $10 \mathrm{mg}$ $/ \mathrm{kg}$ for cases where decaBDE is present in substances; and the unintentional trace contaminant value is set at $500 \mathrm{mg} / \mathrm{kg}$ for the sum of all BDEs, including decaBDE, where they are present in mixtures and articles. In addition, some tasks will be transferred from the European Commission to the European Chemicals Agency (ECHA) relating to administrative, technical and scientific aspects of the implementation of the Regulation and the exchange of information.

The adoption of the EU regulation comes as the ninth meeting of the Conference of the Parties (COP-9) to the Stockholm Convention on Persistent Organic Pollutants (POPs Convention) was held where it was agreed to list dicofol and Perfluorooctanoic acid (PFOA), its salts and PFOA-related com- pounds in Annex A to the Convention; and to amend the listing in Annex B to the Convention of perfluorooctane sulfonic acid (PFOS), its salts and perfluorooctane sulfonyl fluoride (PFOSF).

\section{EU: Chemicals Agency Mapping Legislation Regulating Chemical Substances}

The European Commission has recognised the need to support companies manufacturing, distributing or using chemicals in their ability to understand and fulfil their legal obligations by developing an online service to facilitate identification of relevant legislation. The service is called the European Union Chemical Legislation Finder (EUCLEF) and is currently being worked on by the European Chemicals Agency (ECHA) who will launch the service in $2020^{2}$.

Navigating the extensive EU legislation can be a challenge, particularly when searching for legislation affecting chemicals which can range from being general in nature through to targeting specific substances or groups of chemicals. The service will have mutual benefits for companies and regulators alike; not only will companies have a clearer understanding on the legislation, regulators enforcing legislation will be able to be more specific in their investigations, whilst The European Commission and Member State authorities will be better equipped to identify gaps and overlaps. ECHA already provides information on chemicals via its website, largely based on the data submitted by companies complying with the REACH Regulation. The addition of other information sources on individual chemicals provides the potential for improving knowledge for the chemical industry and wider chemicals stakeholder community.

Meanwhile at the UNEP Open-ended Working Group of the International Conference on Chemicals

DOI: $10.21552 / \mathrm{icrl} / 2019 / 2 / 11$

1 Regulation of the European Parliament and of the Council on persistent organic pollutants (recast), PE-CONS 61/19, 24 May 2019

2 ECHA Newsletter 2, May 2019 
Management in April $2019^{3}$, the International Council of Chemical Associations (ICCA) proposed that sharing of chemical data should be taken to a global level through the creation of a global repository, referred to as an 'international navigator'. ICCA suggests the navigator could make use of data already collected by regional jurisdictions and this would support the development of chemicals management programmes in countries where chemicals legislation is limited or under development, ultimately improving chemical safety around the world.

3 UNEP Open-ended Working Group of the International Conference on Chemicals Management, Third meeting, Montevideo, 2-4 April 2019, Submission of the International Council of Chemical Associations (ICCA) and the United Nations Environment Programme (UNEP): Knowledge Management and Information Sharing for the Sound Management of Industrial Chemicals (SAICM/OEWG.3/INF/28). 